bioRxiv preprint doi: https://doi.org/10.1101/853556; this version posted November 26, 2019. The copyright holder for this preprint (which was not certified by peer review) is the author/funder, who has granted bioRxiv a license to display the preprint in perpetuity. It is made available under aCC-BY-NC-ND 4.0 International license.

Preprint article - Futrega et al., 25 Nov 2019

\title{
Micro-pellet culture reveals that bone marrow mesenchymal stromal cell (BMSC) chondrogenic induction is triggered by a single day of TGF- $\beta 1$ exposure
}

\section{Short title: Brief TGF- $\beta 1$ signals BMSC induction in micro-pellets}

Futrega, Kathryn ${ }^{1,2,3}$; Robey, Pamela G. ${ }^{3}$; Klein, Travis J. ${ }^{2}$; Crawford, Ross W. ${ }^{2}$; and Doran, Michael R. ${ }^{1,3,4,5}$ Author Affiliation:

1 Translational Research Institute (TRI), 37 Kent St, Brisbane, QLD, Australia

2 School of Chemistry, Physics and Mechanical Engineering (CPME), Science and Engineering Faculty (SEF), Institute of Health and Biomedical Innovation (IHBI),

Queensland University of Technology (QUT), Brisbane, Australia

${ }^{3}$ National Institute of Dental and Craniofacial Research (NIDCR), National Institutes of Health (NIH), Department of Health and Human Services, Bethesda, MD, USA

${ }^{4}$ School of Biomedical Sciences, Faculty of Health, Institute of Health and Biomedical Innovation (IHBI), Queensland University of Technology (QUT), Brisbane, QLD,

Australia

${ }^{5}$ Mater Medical Research (MMR), University of Queensland (UQ), Brisbane, QLD, Australia

Corresponding Author: Email: michael.doran@qut.edu.au

Author Contributions: KF, PGR, TJK, RC, and MRD designed research, analysed data, and wrote the paper; KF and MRD performed research

\section{$\underline{\text { Abstract }}$}

Despite immense promise, engineering of stable cartilage tissue from bone marrow-derived stromal cells (BMSCs, also known as bone marrow-derived "mesenchymal stem cells") remains elusive. Relative cartilage-like matrix deposition is commonly used to guide BMSC chondrogenic optimisation efforts. However, matrix deposition is heterogeneous in most models, and notably, it lags behind cell fate decisions. We reason that the lag time between cell fate decision and matrix accumulation, coupled with matrix heterogeneity, has obscured basic BMSC biological characteristics, such as differentiation kinetics. Here, we utilize a customized microwell platform to assemble hundreds of small-diameter BMSC micro-pellets and characterized chondrogenic differentiation kinetics in response to the canonical signaling molecule, transforming growth factor$\beta 1$ (TGF- $\beta 1$ ). Micro-pellets provide a homogeneous readout, and our experimental design accounts for the significant time delay between growth factor signal and deposition of cartilage-like matrix. While 14-to-21-day induction protocols are routine, BMSC micro-pellet cultures reveal that a single day of TGF- $\beta 1$ exposure was sufficient to trigger chondrogenic differentiation cascades resulting in outcomes similar to micro-pellets exposed to TGF- $\beta 1$ for 21 days. RNA-sequencing analysis demonstrated that one day of TGF- $\beta 1$ exposure was also sufficient to induce hypertrophic cascades in BMSC, not observed in articular chondrocytes. Refocusing chondrogenic induction optimisation efforts from weeks to the first hours or days of culture, using homogeneous model systems, may benefit efforts to build stable cartilage formed by BMSCs.

\section{Significance}

The macro-pellet model, and assumptions generated using it, have permeated BMSC-based cartilage tissue engineering strategies since the 1990s. Using a micro-pellet model, we show that BMSC chondrogenic kinetics are significantly more rapid than historical macro-pellets data suggests, and that BMSC chondrogenic and hypertrophic commitment is instructed by a single day of TGF- $\beta 1$ exposure. This highly relevant study demonstrates that: (1) macro-pellets, which are large heterogeneous tissue models confound the differentiation kinetics visible in micro-pellet models; (2) induction strategies should focus on the first hours or days of culture; (3) even a single day of TGF- $\beta 1$ exposure drives BMSC to form hypertrophic tissue in vivo, requiring early intervention to prevent hypertrophy; and (4) articular chondrocytes and BMSCs respond distinctly to TGF- $\beta 1$.

Keywords: bone marrow stromal cells, articular cartilage, chondrocytes, tissue engineering, TGF- $\beta$ 


\section{Preprint article - Futrega et al., 25 Nov 2019}

\section{Introduction}

Bone marrow-derived stromal cells (BMSCs, also known as bone marrow-derived "mesenchymal stem cells") were heralded as a panacea for cartilage repair, but have failed to live up to expectations [1]. While BMSCs appear to have the capacity to differentiate into chondrocytes, current protocols yield temporary, unstable cell populations that evolve to form hypertrophic chondrocytes and mineralized tissue in vivo [1, 2]. Because cartilage is matrix-rich (98\% [3]) and matrix underpins mechanical function, chondrogenic assays are biased toward the use of matrix characterization as a measure of BMSC differentiation. However, matrix accumulation takes time, and thus matrix accumulated at culture end point likely reflects cell fate decisions made days earlier. This temporal complexity is frequently exasperated by the use of macroscopic cartilage tissue models that suffer from profound diffusion gradients, yielding both heterogenous matrix and cell phenotypes $[4,5]$.

Examination of the classic "pellet culture" highlights how temporal and spatial heterogeneity can confound the study of BMSC chondrogenesis. In 1998, Johnstone et al. described the pellet culture (hereafter, referred to as the macro-pellet), which has become the gold standard for differentiating BMSCs into chondrocyte-like cells in vitro [6]. In the original macro-pellet culture, $\sim 2 \times 10^{5}$ BMSC were pelleted in induction medium that critically included supplementation with transforming growth factor- $\beta 1$ (TGF- $\beta 1$ ). Thousands of papers have since used the macro-pellet culture to characterize or optimise the in vitro chondrogenic capacity of BMSCs. Little has changed since the introduction of the macro-pellet culture model, with most studies continuing to use similar numbers of cells per macro-pellet, and several weeks of induction in medium supplemented with one of the TGF- $\beta$ isoforms (TGF- $\beta 1$ or TGF- $\beta 3$ ). Recent reviews of published chondrogenic induction models described the use of TGF- $\beta$ induction ranging from 7 days to 28 days, with macro-pellets containing between $2 \times 10^{5}$ to $1 \times 10^{6}$ BMSCs each $[7,8]$. Other growth factors have been incorporated to enhance chondrogenic induction protocols [7-11], mostly in macro-pellet cultures formed from $>2 \times 10^{5}$ BMSCs each and induction periods ranging from 7-45 days; however, TGF- $\beta$ remains the most important and most commonly used chondrogenic induction factor.

TGF- $\beta$ instructs BMSCs to take on a chondrocyte-like phenotype, and in response, pelleted cells secrete cartilage-like matrix. Macro-pellet cultures evolve to form large (1-3 mm diameter) tissues, yielding large radial diffusion gradients and the development of different cell and tissue types in different regions of the pellet $[4,5]$. The radially heterogeneous matrix distribution that can be observed at different time points suggest that some regions of the macro-pellet undergo differentiation at different rates than other regions of the macro-pellet [5]. While spatial heterogeneity is well-recognized, the potential impact that this imposes on temporal differentiation heterogeneity is rarely discussed. As BMSC chondrogenic differentiation lies on a continuum, where the terminally differentiated cell type is a hypertrophic chondrocyte [12], the temporal response to induction factors is a critical variable. Geometric heterogeneity common in macro-pellet cultures, and other macroscopic tissue models, effectively imposes temporal heterogeneity. Because of these uncontrolled gradients, we reason that fundamental understanding, such as true BMSC induction kinetics in response to factors such as TGF- $\beta 1$ remains unknown. Lack of understanding of induction kinetics has hindered development of protocols that might better control stage-wise differentiation of BMSCs into a cell population capable of producing hyaline cartilage, with reduced propensity to undergo hypertrophic differentiation. Effective bioprocess optimization will require use of platforms that enable manufacture of more homogeneous cartilage-like tissues to quantify induction kinetics and more precisely guide desired tissue outcomes. 


\section{Preprint article - Futrega et al., 25 Nov 2019}

Here, we use a more homogeneous, small diameter micro-pellet model to characterize the temporal influence of TGF- $\beta 1$, the most commonly used BMSC chondrogenic induction factor. We used a high-throughput microwell platform, termed the Microwell-mesh [5], to enable manufacture of thousands of small diameter micro-pellets for this analysis. Because individual micro-pellets $\left(5 \times 10^{3}\right.$ cells each) are formed from fewer cells than macro-pellets ( $2 \times 10^{5}$ cells each), the resulting smaller tissues experience reduced diffusion gradients and yield more homogeneous cartilage-like tissue. For this reason, micro-pellets are a more appropriate model to characterize BMSC chondrogenic differentiation kinetics, compared with the standard macro-pellet model. To account for the disconnect or lag time between cellular response to TGF- $\beta 1$ exposure and cartilage-like matrix accumulation, we used 21-day cultures, where cells were exposed to TGF- $\beta 1$ for different time periods ranging from $0,1,3,7,14$, or 21 days. We contrasted results from micro-pellet and macro-pellet tissues formed from either BMSCs or in vitro expanded articular chondrocytes (ACh). We performed RNA sequencing of micro-pellet cultures at various days $(0,1,3,7$, and 21$)$ of the 21 day culture period and on day 21 following TGF- $\beta 1$ withdrawal (on day 1,3 , and 7). These data reveal the time-dependent cellular response to TGF- $\beta 1$ signalling, as well as provide insight into how different durations of TGF- $\beta 1$ exposure influences BMSC fate. Overall, micro-pellet studies reveal the rapid temporal response of BMSCs to TGF- $\beta 1$ exposure, the influence of TGF- $\beta 1$ programming following TGF- $\beta 1$ withdrawal, the confounding influence that macro-pellet heterogeneity has on perceived differentiation kinetics, and the divergent response of ACh and BMSCs to the TGF- $\beta 1$ stimulus.

\section{$\underline{\text { Results }}$}

TGF- $\beta 1$ is the most common growth factor used in BMSC chondrogenic induction medium. However, because of confounding factors in chondrogenic models, the temporal response of BMSCs to TGF- $\beta 1$ and BMSC differentiation kinetics are uncertain. To determine the temporal influence of TGF- $\beta 1$ on BMSC chondrogenic induction, we tested various TGF- $\beta 1$ exposure times over a fixed culture period of 21 days to account for the lag between cell differentiation and measurable matrix accumulation. Traditional macro-pellet cultures were assembled from $2 \times 10^{5}$ BMSCs each in deep well plates, while micro-pellets were formed from $5 \times 10^{3}$ BMSCs each (40-fold fewer cells per tissue) in Microwell-mesh plates (Fig 1A). In Microwell-mesh plates (Fig 1B), cells in suspension were centrifuged through the openings $(36 \mu \mathrm{m})$ in the nylon meshes bonded over microwells. Cells pelleted in microwells aggregated to form micro-pellets, becoming too large to escape back through the mesh openings, thus being retained in discrete microwells over the culture period. By varying the number of cells per pellet, large macro-pellets ( $2 \times 10^{5} \mathrm{BMSC}$ each) or smaller micro-pellets $\left(5 \times 10^{3}\right.$ BMSC each) were produced. Larger diameter pellets inherently suffer from increased diffusion gradients of metabolites, gases, and other factors (Fig 1C) [13, 14], while gradients are reduced in smaller diameter pellets, yielding more homogeneous cartilage-like tissue [4, 5]. Induction cultures consisted of basal chondrogenic medium supplemented with TGF- $\beta 1$ for either $0,1,3,7$, 14, or 21 days of the total 21-day induction culture. Each culture condition is represented by a horizontal line in Fig 1D, with blue and grey lines representing days with (+)TGF- $\beta 1$ and without (-)TGF- $\beta 1$, respectively, and the red arrow specifying the day of analysis. On the indicated day, TGF- $\beta 1$ was eliminated (washed away) and replaced with basal medium for the remainder of the 21-day culture. Parallel cultures were established using BMSCs from 4 unique donors and ACh from two unique donors. 
Preprint article - Futrega et al., 25 Nov 2019

A

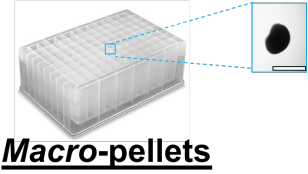

Deep well plates: $2 \times 10^{5}$ cells/well

$2 \times 10^{5}$ cells/macro-pellet

1 macro-pellet/well

B
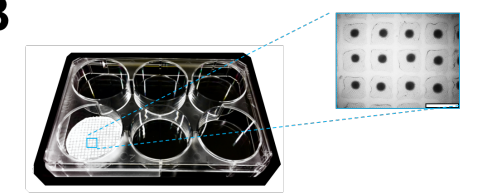

Micro-pellets

Microwell-mesh: $1.25 \times 10^{6}$ Cells/well $5 \times 10^{3}$ cells/micro-pellet 250 micro-pellets/well
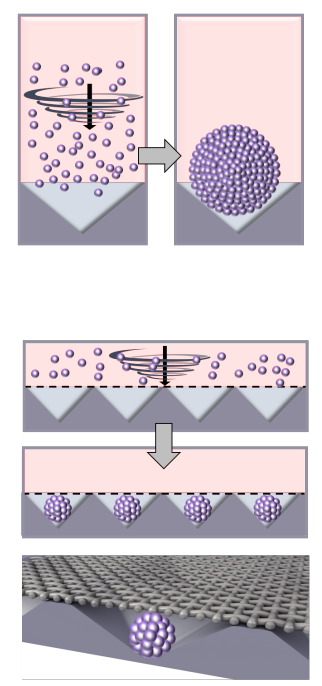

C Macro-pellets

Micro-pellets

Gradients reduced

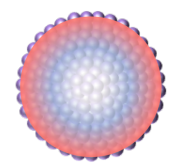

D

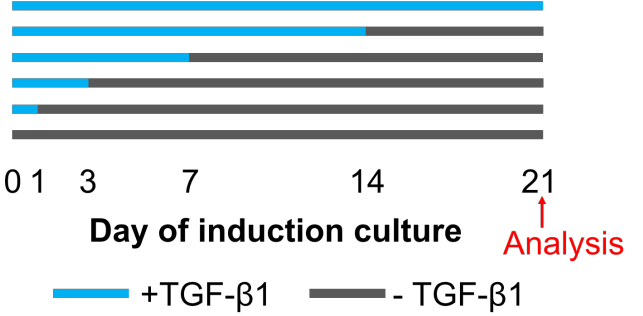

Figure 1. Schematic of experimental procedures. (A, B) Different cell seeding densities were used to generate macro-pellets or micro-pellets of specific size in deep well plates or Microwell-mesh plates, respectively. Micro-pellets were retained in discrete microwells by the nylon mesh bonded over the microwell openings. Retention by the mesh enabled long-term micro-pellet culture, including multiple medium exchanges to add or deplete cultures of TGF- $\beta 1$. (C) Diffusion gradients are reduced in smaller diameter micro-pellets relative to larger diameter macro-pellets [13, 14]. (D) Cultures were carried out for 21 days total, with blue lines representing culture days with TGF- $\beta 1$ in the medium, and grey lines representing culture days without TGF- $\beta 1$ in the medium.

\section{Gross Morphology and Histology}

Gross photographic and microscopic images, and Toluidine blue stained sections for BMSCand $A C h$-induced chondrogenic tissues exposed to TGF- $\beta 1$ for $0,1,3,7,14$, or 21 days are shown in Fig 2 and 3, respectively. Overall, tissue growth was greater in micro-pellets than in macro-pellets (Fig 2A). On average, the diameter of macro-pellets exposed to TGF- $\beta 1$ for 21 days was 2.2 times greater than macro-pellets not exposed to TGF- $\beta 1$ (Day 0), while the diameter of micro-pellets exposed to TGF- $\beta 1$ for 21 days was 3.7 times greater in diameter than micro-pellets not exposed to TGF- $\beta 1$ (Day 0). Relative cartilage-like tissue volume was approximately $25 \%$ greater per input cell when BMSCs were cultured as micro-pellets with 21 days TGF- $\beta 1$ exposure, relative to matched BMSC macro-pellet controls. In macro-pellet cultures, tissues grew incrementally larger with extended TGF- $\beta 1$ exposure. By contrast, micro-pellets achieved the majority of tissue growth in response to a single day of TGF- $\beta 1$ exposure (approximately $75 \%$ of maximum micro-pellet diameter was achieved in response to a single day of TGF- $\beta 1$ exposure).

Toluidine blue histological staining was used to characterize spatial glycosaminoglycan (GAG) content in the tissue matrix. Both BMSC macro-pellet and micro-pellet cultures that were not supplemented with TGF- $\beta 1$ during the induction period remained small (Fig 2A) and had little GAG staining in their matrix (Fig 2B). BMSC macro-pellets exposed to TGF- $\beta 1$ for less than 21 days, simultaneously had regions of undifferentiated tissue (weak Toluidine blue GAG staining) and regions of differentiated tissue (strong Toluidine blue GAG staining) (Fig 2B). In BMSC micro-pellets, GAG staining was relatively uniform across the diameter of tissues, and strong GAG staining was visible even with a single day of TGF- $\beta 1$ exposure (Fig 2B). Substantial BMSC donor variability was observed in macro-pellets when the duration of TGF- $\beta 1$ exposure was short (i.e. less than 14 days). However, donor variability was less evident in micro-pellet cultures, with all BMSC populations 
bioRxiv preprint doi: https://doi.org/10.1101/853556; this version posted November 26, 2019. The copyright holder for this preprint (which was not certified by peer review) is the author/funder, who has granted bioRxiv a license to display the preprint in perpetuity. It is made available under aCC-BY-NC-ND 4.0 International license.

\section{Preprint article - Futrega et al., 25 Nov 2019}

yielding tissue that stained intensely and uniformly with Toluidine blue, even with only 1 day of TGF$\beta 1$ exposure (Fig 2B).

The biochemical content, including GAG, DNA and GAG/DNA, for BMSC macro- and micropellets is shown in Fig $\mathbf{2 C}$. Cultures that received TGF- $\beta 1$ for the full 21 days were considered the control (shown to the right of dashed lines in Fig $\mathbf{2 C}$ ), and cultures with different durations of TGF$\beta 1$ exposure were compared with these controls. In BMSC macro-pellet cultures, two of four BMSC donors reached maximal GAG content with 14 days of TGF- $\beta 1$ exposure, while one donor required the full 21 days of TGF- $\beta 1$ exposure (Fig 2C). In BMSC micro-pellet cultures, three of four BMSC donors reached maximum GAG content with 3 days of TGF- $\beta 1$ exposure, while one donor reached this maximum value with 1 day of TGF- $\beta 1$ exposure. In BMSC macro-pellet cultures, DNA content increased steadily with increasing TGF- $\beta 1$ exposure days, with two donors reaching maximum DNA content with 14 days of TGF- $\beta 1$ exposure and two requiring 21 days of TGF- $\beta 1$ exposure. In BMSC micro-pellet cultures, DNA content also increased with increasing TGF- $\beta 1$ exposure, with two donors reaching maximum DNA content with 1 day of TGF- $\beta 1$ exposure and two donors reaching maximum DNA content with 3 or 7 days of TGF- $\beta 1$ exposure.

For BMSC macro-pellets, maximum GAG/DNA was variable, with two BMSC donors (BMSC 3 and 4) reaching the maximum GAG/DNA content with 1 day of TGF- $\beta 1$ exposure, and two donors (BMSC 1 and 2 ) required 14 and 21 days of TGF- $\beta 1$ exposure, respectively. By contrast, BMSC micropellets maximum GAG/DNA was achieved with reduced TGF- $\beta 1$ exposure. BMSC donors 3 and 4 reached maximum GAG/DNA content with 1 day of TGF- $\beta 1$ exposure, while BMSC donors 1 and 2 required 3 and 7 days of TGF- $\beta 1$ exposure, respectively. As the GAG and DNA quantification assay was only performed at day 21 of culture, it is not possible to determine at what rate the GAG or DNA content was produced and whether TGF- $\beta 1$ might influence the rate of GAG or DNA production differently.

Overall, fewer days of TGF- $\beta 1$ exposure in micro-pellet BMSC cultures were required to obtain GAG quantities equivalent to control culture having 21 days of TGF- $\beta 1$ exposure, compared to traditional macro-pellet BMSC cultures. Spatial distribution of Toluidine blue staining demonstrated uniform and high levels of GAG deposition in micro-pellet tissues with as little as 1 day of TGF- $\beta 1$ exposure, while GAG deposition in macro-pellets required 14-21 days TGF- $\beta 1$ exposure before achieving similar uniformity. 
A
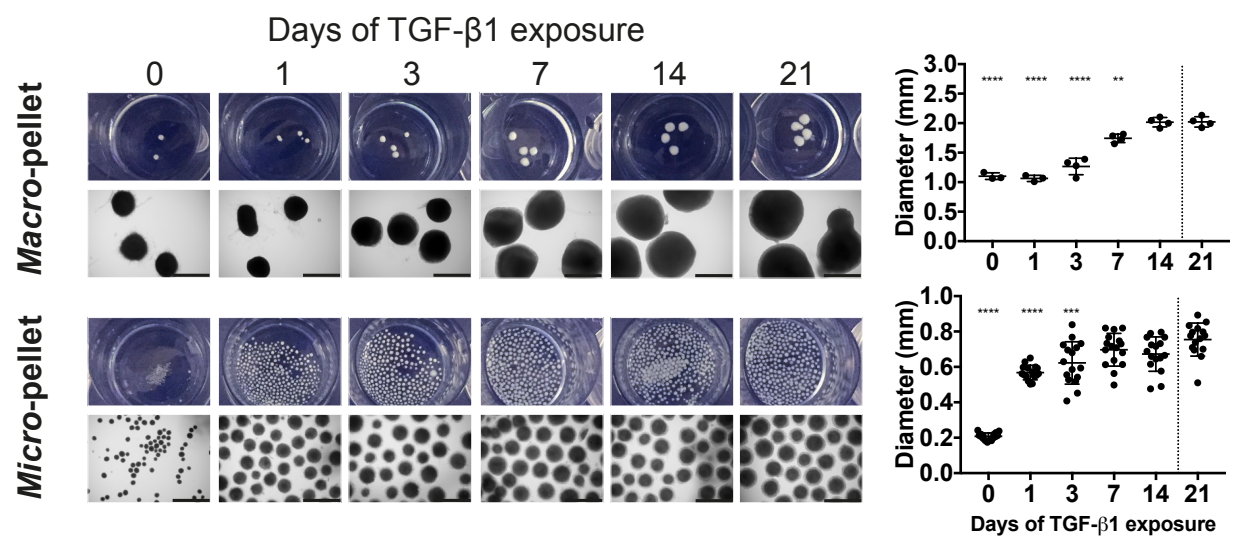

B
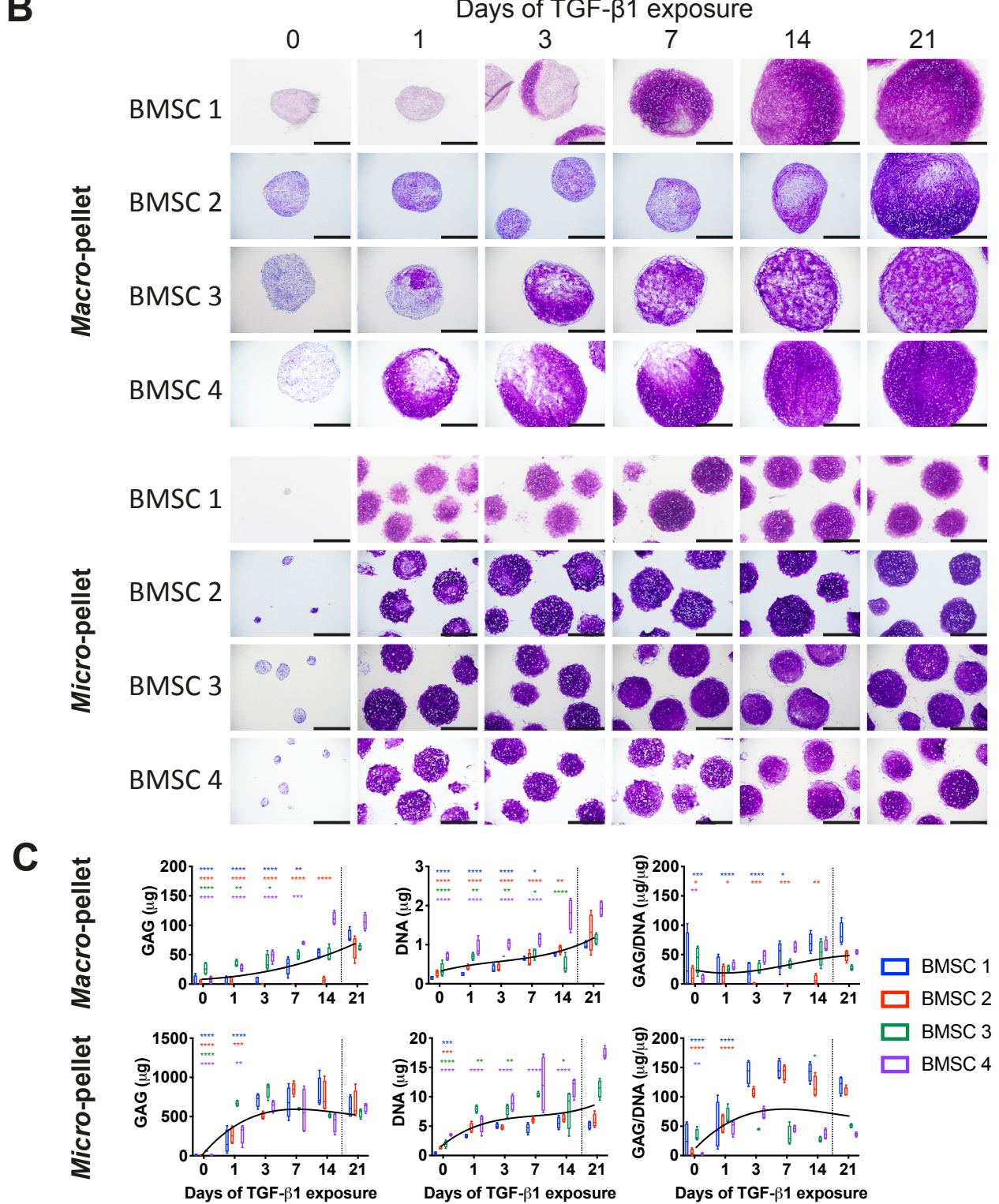

Figure 2. Cartilage-like tissues derived from BMSCs after 21 days in vitro differentiation with TGF$\beta 1$ exposure for the number of days indicated. (A) Gross photographs and brightfield microscopy images of whole BMSC-derived tissues (scale bars for microscopy images, $1 \mathrm{~mm}$ ), and corresponding diameters. (B) Toluidine blue stain of macro- and micro-pellet tissue cross-sections are shown for four unique BMSC donors (scale bars, $500 \mu \mathrm{m}$ ). (C) GAG, DNA, and normalized GAG/DNA quantification for each BMSC donors. Asterisks are shown for values that are significantly lower than the corresponding 21 days of TGF- $\beta 1$ exposure control. Values represent mean $\pm S D ; n=4 ;{ }^{*} P$ $<0.05,{ }^{* *} \mathrm{P}<0.01,{ }^{* * *} \mathrm{P}<0.001$, and ${ }^{* * * *} \mathrm{P}<0.0001$. 
bioRxiv preprint doi: https://doi.org/10.1101/853556; this version posted November 26, 2019. The copyright holder for this preprint (which was not certified by peer review) is the author/funder, who has granted bioRxiv a license to display the preprint in perpetuity. It is made available under aCC-BY-NC-ND 4.0 International license.

\section{Preprint article - Futrega et al., 25 Nov 2019}

ACh macro- and micro-pellet cultures (Fig 3) had a different pattern of behaviour compared with their equivalent BMSC pellet cultures described above. ACh-derived macro-pellets appeared similar in size with varied TGF- $\beta 1$ exposure following 21 days of culture (Fig 3A). Unlike spherical BMSC-derived tissues, ACh macro-pellets exhibited a cup-like structure with a concaved centre (see red arrows pointing to side views in Fig 3A). This cup-like structure was not observed in ACh micropellets, which were spherical like BMSC micro-pellets, but required more than 7 days of TGF- $\beta 1$ exposure to grow to the same extent as ACh cultures exposed to TGF- $\beta 1$ for the full 21-day culture period. Like BMSC macro-pellets, ACh macro-pellets benefited from longer TGF- $\beta 1$ exposure, as evidenced by the gradual increase in pellet size (Fig 3A) and increased GAG content, with increasing days of TGF- $\beta 1$ exposure (Fig 3B-C). However, unlike BMSC micro-pellets, ACh micro-pellets required prolonged TGF- $\beta 1$ exposure for increased growth (Fig 3A), and GAG production. ACh macro- and micro-pellets demonstrated reduced GAG staining (Fig 3B) and content (Fig 3C) when TGF- $\beta 1$ was withdrawn early in the 21-day culture period. In both macro- and micro-pellet culture, ACh donor 2 appeared to be a more potent cartilage-matrix producing cell population, compared with ACh donor 1, as donor 2 cells produced more intense GAG staining (Fig 3B) and GAG quantity (Fig 3C). Culturing ACh 1 as micro-pellets did improve the potency of this donor, possibly due to increasing the cells' proliferative capacity as seen by the substantial increase in DNA content in micro-pellets, compared with the very low rate of DNA content increase in the macro-pellets (Fig $\mathbf{3 C}$ ). The differences in growth, GAG and DNA production between ACh and BMSC-derived tissues may be explained by the fact that our ACh were of later passage than BMSC (P6 vs. P3, respectively). Additionally, as ACh are considered to be differentiated cells, the mechanisms of TGF- $\beta 1$ action on these cells are likely to be substantially different than on multipotent BMSCs undergoing a fate choice and differentiation in vitro. 
A Days of TGF- $\beta 1$ exposure

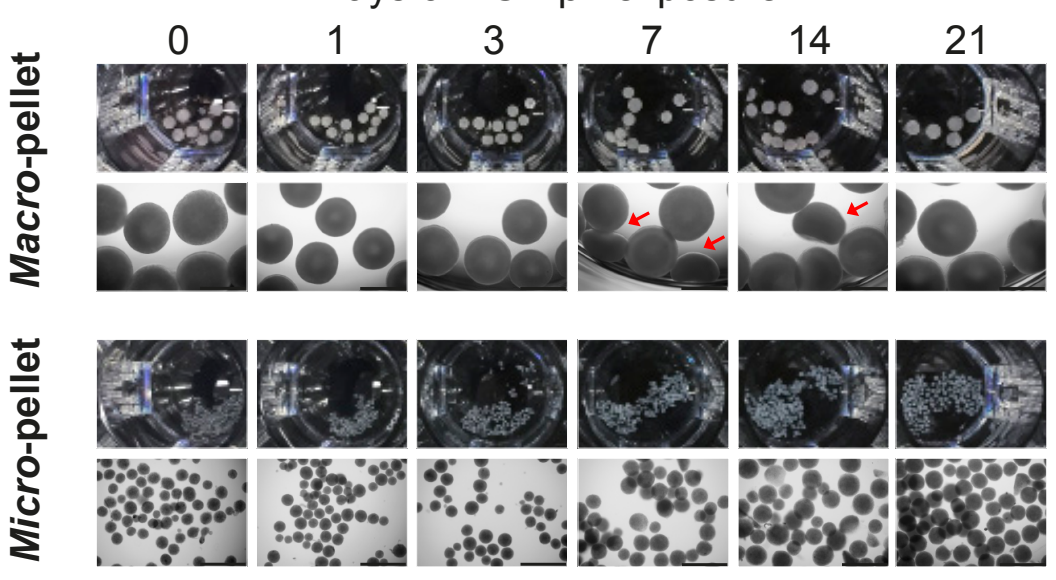

B

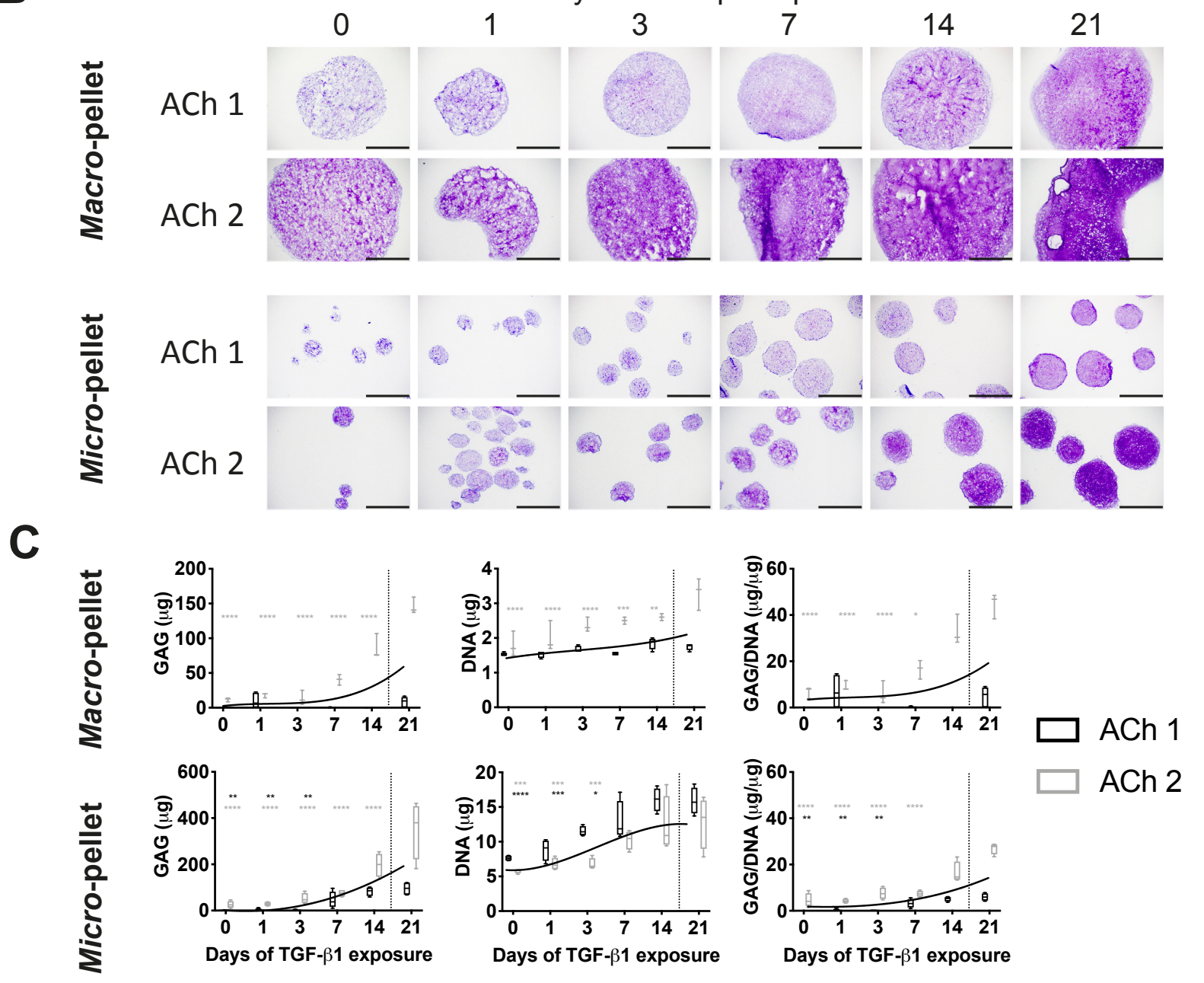

Figure 3. Cartilage-like tissues derived from ACh after 21 days in vitro differentiation with TGF- $\beta 1$ exposure for the number of days indicated. (A) Gross photographs and brightfield microscopy images of whole ACh-derived tissues (scale bars for microscopy images, $1 \mathrm{~mm}$ ), and corresponding diameters. (B) Toluidine blue stain of macro- and micro-pellet tissue cross-sections are shown for two unique ACh donors (scale bars, $500 \mu \mathrm{m}$ ). (C) GAG, DNA, and normalized GAG/DNA quantification for $A C h$ donors. Asterisk are shown for values that are significantly lower than the corresponding 21 days of TGF- $\beta 1$ exposure control. Values represent mean $\pm S D ; n=4 ; * P<0.05,{ }^{* *} P$ $<0.01, * * * \mathrm{P}<0.001$, and $* * * * \mathrm{P}<0.0001$. 
bioRxiv preprint doi: https://doi.org/10.1101/853556; this version posted November 26, 2019. The copyright holder for this preprint (which was not certified by peer review) is the author/funder, who has granted bioRxiv a license to display the preprint in perpetuity. It is made available under aCC-BY-NC-ND 4.0 International license.

\section{Preprint article - Futrega et al., 25 Nov 2019}

\section{qPCR Analysis}

We assessed the relative expression of genes associated with chondrogenesis (SOX9, COL2A1, ACAN) and hypertrophy (COL1A1, COL1OA1, and RUNX2) for both macro- (Fig 4A) and micro-pellet (Fig 4B) cultures. Each TGF- $\beta 1$ exposure condition was compared with the standard control culture, where TGF- $\beta 1$ was maintained for the entire 21 days (shown to the right of dashed lines in Fig 4).

In macro-pellets, substantial variability was observed between different cell donors. While both chondrogenic and hypertrophic genes tended to increase with extended TGF- $\beta 1$ exposure, these were not statistically significant for all donors and at all time points analyzed. Micro-pellet cultures yielded more consistent gene expression changes. This outcome can, in part, be related to the greater magnitude in gene expression values observed in micro-pellet cultures (Fig 4). For each BMSC donor, relative SOX9 expression was statistically equivalent or greater for cultures that only received 1-14 days of TGF- $\beta 1$ exposure, compared with the control. Relative COL2A1 and ACAN expression was comparable to the 21-day control condition with 1 day of TGF- $\beta 1$ exposure for BMSC donors 3 and 4 , and 3 days for BMSC donors 1 and 2 .

The expression of COL1OA1 in micro-pellets formed from BMSC donors 3 and 4 reached 21day control levels with 1 day of TGF- $\beta 1$ exposure, while micro-pellets formed from BMSC donor 2 required 3 days of TGF- $\beta 1$ exposure, and BMSC donor 1 required 7 days of TGF- $\beta 1$ exposure. $R U N X 2$ expression was only significantly lower for BMSC donor 2 when TGF- $\beta 1$ was washed out at days 1 , 3,7 , or 14, compared with the 21-day control. COL1A1 expression in BMSC micro-pellets was the only gene that declined significantly when TGF- $\beta 1$ was washed out on one or more of the washout days (day $1,3,7$, or 14 ) for all donors. For ACh, ACAN expression declined when TGF- $\beta 1$ was washed out at days $1,3,7$, or 14 , but this was only significant for one of the two ACh donors, ACh 1 . No hypertrophy gene expression was observed in cultures from either of the two ACh donors.

Overall, qPCR analysis suggested that 1-3 days of BMSC micro-pellet exposure to TGF- $\beta 1$ was sufficient to induce chondrogenic genes, and this same brief TGF- $\beta 1$ exposure appeared to also upregulate hypertrophy genes, as measured in the 21-day control cultures. 
A

Chondrogenic
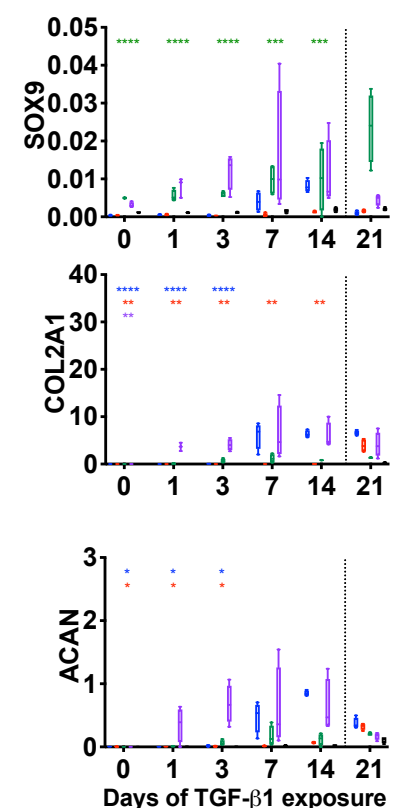

BMSC 1

\section{Macro-pellet}

Hypertrophic
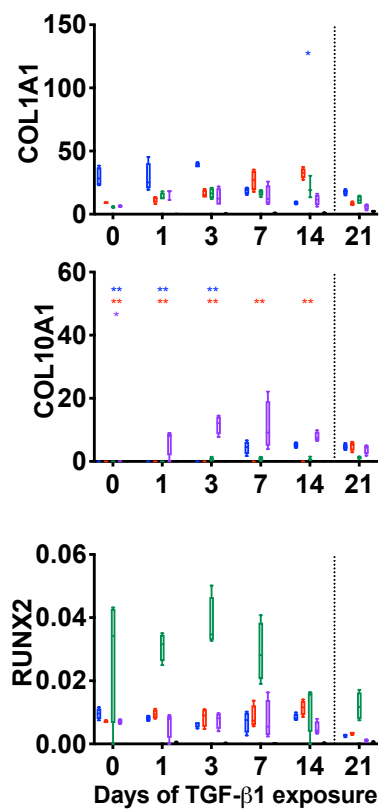

Preprint article - Futrega et al., 25 Nov 2019

\section{B Micro-pellet}

Chondrogenic
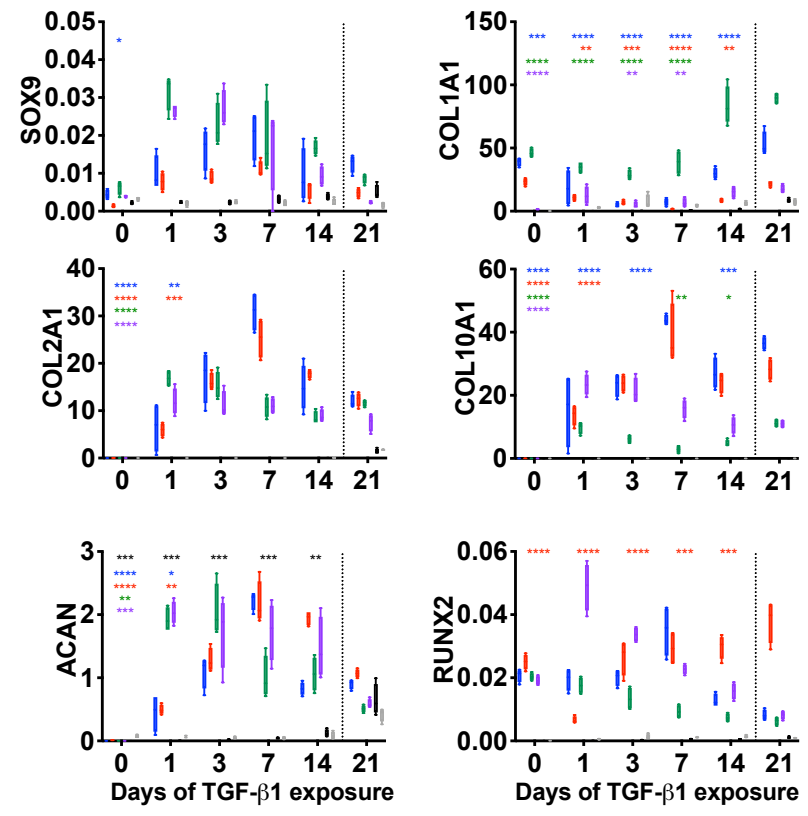

BMSC $4 \square$ ACh 1
Hypertrophic
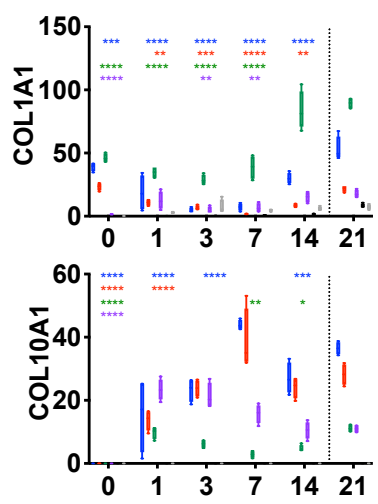

BMSC $2 \square$ BMSC 3

Figure 4. $\mathrm{PPCR}$ analysis of cartilage-like tissues derived from BMSCs or ACh on day 21 of culture, following varying days of TGF- $\beta 1$ exposure. (A) qPCR from macro-pellet cultures, (B) qPCR from micro-pellet cultures. All values are compared with the standard 21 days of TGF- $\beta 1$ exposure control (separated by the dotted line). Relative gene expression represents $\triangle C$ t values normalized to GAPDH expression. Asterisks are shown for values that are significantly lower than the corresponding 21 days of TGF- $\beta 1$ exposure control. Values represent mean $\pm S D ; n=4 ;{ }^{*} P<0.05,{ }^{* * P}<0.01,{ }^{* * * P}<$ 0.001 , and ${ }^{* * * *} \mathrm{P}<0.0001$.

\section{In vivo subcutaneous hypertrophy}

To confirm our qPCR analysis, which showed that even with reduced TGF- $\beta 1$ exposure, BMSC micro-pellets still appeared to express high relative levels of the hypertrophic marker, COL1OA1, we packed micro-pellets into bovine osteochondral defect models and transplanted them subcutaneously in NSG mice for 8 weeks using a previously established method [15]. Histological examination of tissues showed that, unlike ACh-derived micro-pellets, BMSC-derived micro-pellets exhibited a hypertrophic appearance based on diminished GAG staining and significant recruitment of blood cells, forming a bone marrow like tissue (Fig 5A). Micro-CT analysis confirmed that, unlike differentiated ACh micro-pellets, BMSC micro-pellets formed mineralized tissue in vivo regardless of TGF- $\beta 1$ exposure duration (Fig 5B). Micro-pellets exposed to TGF- $\beta 1$ for 3 days yielded mineralized tissue, with a density similar to the bovine subchondral bone contained in the plug of the joint used to develop the artificial cartilage defect model. ACh micro-pellets formed continuous fill, but individual micro-pellets were still discernible. While not mineralized, the GAG staining of ACh micro-pellets was faint, suggesting that the cartilage-like tissue may be low quality. It may be possible to improve the tissue quality by using lower passage ACh; however, maintaining low passage ACh, while generating sufficient cartilage-defect fill material is a significant limitation in the use of ACh. 


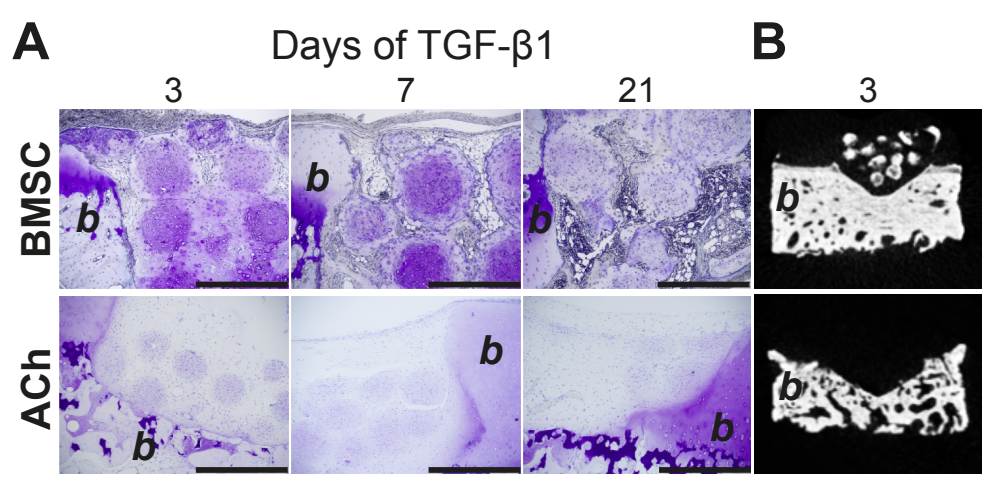

Figure 5. Analysis of micro-pellets implanted subcutaneously in NSG mice for 8 weeks in bovine defect models. (A) Histological sections showed that BMSC and ACh micro-pellets appeared highly remodelled with reduced GAG staining (Toluidine blue), and only BMSC formed bone marrow-like tissues (scale bars, $500 \mu \mathrm{m}$ ). (B) Micro-CT analysis confirmed the presence of mineralized tissue in BMSC micro-pellets, unlike ACh micro-pellets. Representative images are shown for 21 day in vitro differentiated tissues with TGF- $\beta 1$ exposure for days indicated on top of the images. Surrounding bovine cartilage and bone tissue is marked with the letter " $b$ " to indicate bovine tissue.

\section{RNA-Seq Analysis}

To investigate which genes where modified by TGF- $\beta 1$ in BMSC and ACh cultures and identify potential targets to inhibit hypertrophy, we performed bulk RNA-seq analysis. We analysed cultures before induction (Day 0 ) and harvested on day 1, 3, 7, and 21 of culture induction in the presence of TGF- $\beta 1$. On each day, we analysed three BMSC donors (BMSC 1,2 , and 3 ) and two ACh donors (ACh 1 and 2). Additionally, we analyzed one BMSC donor (BMSC 1) and one ACh donor (ACh 2) on day 21 that was exposed to TGF- $\beta 1$ for 1,3 , or 7 days of the total 21-day culture. A schematic of the experiment is shown in Fig 6A with blue and grey lines representing culture days with (+)TGF$\beta 1$ and without (-)TGF- $\beta 1$, respectively, and red arrows representing the day of analysis.

As shown in the multi-dimensional scaling (MDS) in Fig 6B, the three BMSC donors analyzed on a specific day after TGF- $\beta 1$ treatment clustered well with each other at each time point. With incremental culture in TGF- $\beta 1$-supplemented medium, BMSC gene expression shifted to the upper left corner of the plot for all BMSC donors. When 21-day cultures were replicated with BMSC donor 1 (open blue points), but with TGF- $\beta 1$ eliminated from cultures at day $1,3,7$, or 21 , gene expression converged on a common signature identified in the green oval on the MDS plot. This clustering of day 21 cultures, regardless of the length of TGF- $\beta 1$ exposure, confirmed that even with as little as 1 day of TGF- $\beta 1$ exposure, BMSCs are fated to undergo a chondrogenic and hypertrophic differentiation program. Importantly, BMSCs and ACh did not converge in the MDS plot, showing dissimilarity in gene expression, despite being kept under identical culture conditions. While ACh that had been exposed to fewer days of TGF- $\beta 1$ (open grey points) clustered closely together on day 21 , they did not completely overlap with ACh that had been exposed to TGF- $\beta 1$ for the full 21-day culture duration. This suggests that, unlike BMSCs, ACh might undergo a de-differentiation, or other, transcriptional program in response to the withdrawal of TGF- $\beta 1$ signal. 
A

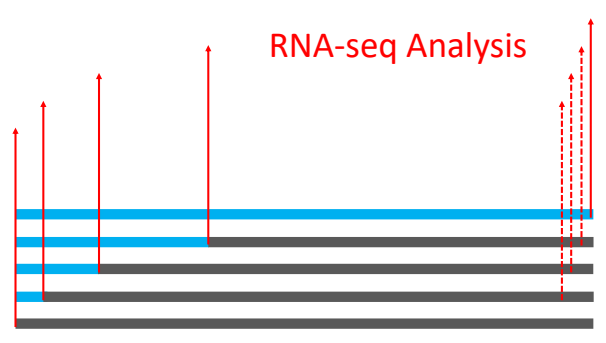

013 Day of Induction Culture + +TGF- $\beta 1$

C
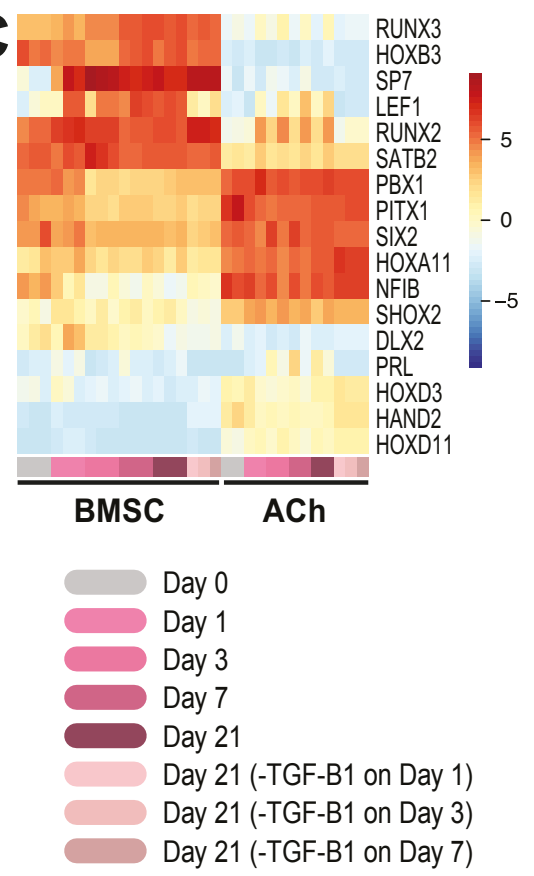

21 TGF- $\beta 1$
B

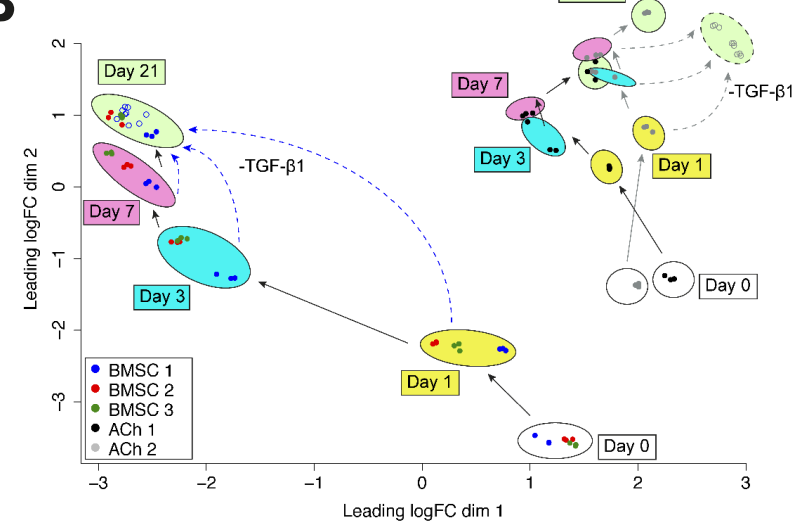

Figure 6. RNA-Sequencing analysis. (A) Whole transcriptome analysis was performed for BMSC and ACh cultures treated with TGF- $\beta 1$ (blue lines) and harvested on day $0,1,3,7$ and 21 as indicated by the solid red arrows (BMSC donors 1, 2, and 3, and ACh donor 1 and 2). Additionally, for BMSC donor 1 and ACh donor 2, RNA-seq analysis was performed on day 21 following TGF- $\beta 1$ withdrawal on day 1,3 , and 7 , represented by dashed red arrows. (B) Multidimensional scaling (MDS) plot showing convergence of BMSC gene expression by day 21, despite withdrawal of exogenous TGF$\beta 1$ in some samples on day 1,3 , or 7 , and dissimilarity to ACh samples treated in the same way. (C) Differentially expressed genes related to osteochondral transcription factors (left), soluble factors and receptor signalling (middle), and ECM molecules and ECM biosynthesis (right). Each timepoint in the heatmap is represented by a color shown on the bottom row of the heatmap, which corresponds to the color key on the bottom left of the figure. Each BMSC timepoint has 3 columns, representing 3 unique BMSC donors, and each ACh timepoint has 2 columns, representing 2 unique ACh donors; only one BMSC donor and one ACh donor was sequenced on day 21 with TGF- $\beta 1$ withdrawal on day 1,3 , or 7 , and are represented by the lighter pink shades; heatmap colors represent the average of three normalized logCPM values. 


\section{Preprint article - Futrega et al., 25 Nov 2019}

At each of the timepoints that we performed RNA-seq, we analyzed the data for differentially expressed genes between BMSCs and ACh (see Supplementary Table 1). We aimed to produce a list of genes that could be useful for detecting early markers of BMSC hypertrophy or as targets to mitigate hypertrophy. We compiled a list of genes that were consistently differentially expressed (>2 log fold) between BMSC and ACh samples on days 3, 7, and 21 , which resulted in a list of 947 genes. We assessed this list of genes against gene ontology terms related to cartilage development (GO:0051216) and ossification (GO:0001503) [16], reducing the list to 77 relevant genes. We further categorized this list into genes related to transcription factors, soluble factors and receptor signalling, and ECM molecules and ECM biosynthesis, and plotted the gene logCPM values for each sample to generate heatmaps (Fig 6C).

Genes for transcription factors that were expressed higher in BMSCs, compared with ACh, included RUNX3, HOXB3, SP7, LEF1, RUNX2, and SATB2. Of these, SP7 and LEF1 were specifically up-regulated in response to TGF- $\beta 1$ exposure in BMSCs. However, unlike LEF1, SP7 remained highly expressed on day 21 even with the withdrawal of TGF- $\beta 1$ on day 1,3 , or 7 . Because SP7 was only highly expressed following TGF- $\beta 1$ induction and maintained this level of expression even after TGF$\beta 1$ withdrawal, SP7 expression might be the most reliable early transcription factor to detect BMSC hypertrophic fate. A number of genes for transcription factors were significantly higher in ACh, compared with BMSCs, but these genes did not appear to change exclusively in response to TGF- $\beta 1$ or its withdrawal. Many of the transcription factors that were expressed higher in ACh, including a number of HOX genes, PBX1 [17], PITX1 [18], SIX2 [19], NFIB [20], and SHOX2 [21], have been associated with patterning and early musculoskeletal progenitor cells.

Genes associated with soluble signalling factors and receptors that were differentially expressed between BMSCs and ACh were largely related to TGF- $\beta$ superfamily signalling, the WNT signalling pathway, and a few others. IHH, WNT11, WNT4 [22], and BMP2 [23] are associated with cartilage hypertrophy, and in our study they were upregulated by a single day of TGF- $\beta 1$ exposure in BMSCs, and their expression remained elevated following its withdrawal. PTH1R expression, which is associated with bone formation and resorption [24], was expressed significantly higher in BMSCs compared with $A C h$, in response to any duration of TGF- $\beta 1$ exposure. ACh expressed higher levels of PTHLH, a known modulator of cartilage hypertrophy [25], than BMSC, in the presence of TGF- $\beta 1$, but not following its withdrawal. Chondrocyte-associated factors from the TGF- $\beta$ superfamily, GDF5, GDF6 [26] and TGFBR3 [27], were consistently expressed in ACh, but were underexpressed by TGF- $\beta 1$ exposure in BMSCs. BMP antagonists GREM1 and $C H R D$ were expressed by both BMSCs and ACh prior to induction (Day 0 ) and in the presence of TGF- $\beta 1$, with higher relative expression in ACh, and decreased in both cell types following TGF- $\beta 1$ withdrawal. FGF-18, a mitigator of hypertrophy [28], was expressed higher in ACh than BMSCs at each timepoint and regardless of TGF- $\beta 1$ exposure or following its withdrawal.

In both BMSCs and ACh, the expression of genes related to ECM molecules and ECM biosynthesis that were responsive to TGF- $\beta 1$ were typically upregulated within either 1 day, or by 3 days, of TGF- $\beta 1$ exposure, and generally remained upregulated following TGF- $\beta 1$ withdrawal with some exceptions in ACh. In both BMSCs and ACh, PRG4 and CILP were upregulated after 1 day of TGF- $\beta 1$ exposure, with overall greater expression in ACh, even following TGF- $\beta 1$ withdrawal. In BMSCs, but not $A C h$, genes associated with ECM mineralization were upregulated including IBSP, $S P P 1$, and PHOSPHO1, but required more than 1 day of TGF- $\beta 1$ exposure and remained highly expressed following its withdrawal. The upregulation of ECM molecule genes associated with cartilage and bone development including COL2A1, HAPLN1, COL1OA1, and COL11A2 required more 


\section{Preprint article - Futrega et al., 25 Nov 2019}

than 1 day of TGF- $\beta 1$ exposure in BMSCs, but remained highly expressed despite TGF- $\beta 1$ withdrawal. While COL2A1 and ELN expression in ACh was generally increased with prolonged TGF- $\beta 1$ expression, TGF- $\beta 1$ withdrawal significantly reduced the level of their expression. A low expression of the hypertrophic ECM molecule gene COL1OA1 was detected in ACh prior to induction and during TGF- $\beta 1$ exposure, but this expression dropped dramatically following TGF- $\beta 1$ withdrawal.

\section{Discussion}

Limitations with ACh-based therapies for cartilage repair are driving investment into therapies that utilize BMSCs or other cell populations [29]. The most commonly evaluated alternative cell populations are bone marrow-derived cells (31\%, including BMSCs) [29]. However, the progression of prospective therapies using bone marrow-derived cells to phase III trials is low (3.2\% [29]), and no BMSC cartilage repair therapies have attained FDA approval. We reason that significant knowledge gaps in the understanding of BMSC chondrogenic differentiation play a major role in the failure of BMSCs to achieve cartilage repair expectations [1].

For over two decades, researchers have been using the pellet culture, in which several hundred-thousand BMSCs are pelleted in a tube containing medium supplemented with TGF- $\beta 1$ ([6]; referred to as the macro-pellet in this manuscript) to study this differentiation process. However, this is a spatially and temporally heterogeneous model, which obfuscates the effects of the differentiation media.

Increasingly, the propensity of BMSCs to form hypertrophic tissue has been acknowledged as a barrier to successful clinical translation [1], and this has become an area of active research. Studies have reported successful obstruction of hypertrophy and formation of stable articular cartilage-like tissue by: (1) manipulation of WNT signalling [30, 31]; (2) silencing of BMP receptor signalling via a proprietary molecule [32]; (3) provision of different soluble factors on opposite sides of a cartilage-like disc to replicate an osteochondral interface [33]; or (4) use of novel scaffolds [34]. While promising, a recent article critically notes that these studies have yet to be replicated by independent groups [35]. A common feature of previous studies was the use of large tissue models and extended TGF- $\beta$ exposure. For example, Narcisi et al., used $2 \times 10^{5}$ BMSC per macro-pellet and 5 weeks induction (10 ng/mL TGF- $\beta 1$ ) [30], Yang et al., 2.5×105 BMSC per macro-pellet and 14-35 days induction ( $5 \mathrm{ng} / \mathrm{mL}$ TGF- $\beta 3$ ) [31], Occhetta et al., 2.5×105 BMSC per macro-pellet and 14 days induction (10 ng/mL TGF- $\beta 3$ ) [32], $\mathrm{Ng}$ et al., multiplex layers of $2.5 \times 10^{5} \mathrm{BMSC}$ and 10 weeks induction (10 ng/mL TGF- $\beta 3$ ) [33]. Physically large tissues, generated from hundreds of thousands of cells, suffer diffusion gradients resulting in spatial tissue heterogeneity. The desired stable highquality cartilage-like tissue may have formed in regions of these macro-tissues, but likely tissue quality varied spatially.

Our group has been a proponent of using smaller diameter micro-pellets to generate more homogeneous tissues $[4,5]$, reasoning that a homogeneous readout is necessary for optimizing a complex bioprocess such as BMSC chondrogenesis. Here we studied BMSC differentiation in response to the canonical induction factor, TGF- $\beta 1$, using a micro-pellet model ( $5 \times 10^{3} \mathrm{BMSCs}$ each) and a traditional macro-pellet model ( $2 \times 10^{5} \mathrm{BMSC}$ each). We reasoned that in addition to the confounding heterogeneity of macro-pellet models, the use of cartilage-like matrix quantification as the readout for BMSC chondrogenesis can be misleading. Cartilage-like matrix deposition must necessarily lag behind the BMSC chondrogenic fate decision, introducing a significant delay in matrix readouts. As chondrocytes lie on a continuum between skeletal stem/progenitor cells, and hypertrophic chondrocytes, or bone-forming cells [1], a presumably temporal exposure of BMSCs to induction factors is likely to be a critical consideration in the optimisation of chondrogenesis 


\section{Preprint article - Futrega et al., 25 Nov 2019}

protocols. To account for a lag in matrix deposition, we titrated the duration of TGF- $\beta 1$ exposure $(0,1,3,7,14$, or 21 days), but maintained all cultures for 21 days to allow cell fate decisions to manifest and for matrix to accumulate

Physical tissue size provided an immediate indication that the kinetics of BMSC micro- and macro-pellets response to TGF- $\beta 1$ exposure differed. As expected, extended TGF- $\beta 1$ exposure resulted in incrementally larger BMSC macro-pellets. BMSC macro-pellet GAG and GAG/DNA quantities increased incrementally with extended TGF- $\beta 1$ exposure. Unexpectedly, a single day of TGF- $\beta 1$ exposure yielded BMSC micro-pellets that grew to a size nearly equivalent to micro-pellets exposed to TGF- $\beta 1$ for 21 days. Biochemical characterization similarly indicated that brief exposure of BMSC micro-pellets to TGF- $\beta 1$ was sufficient to yield GAG and GAG/DNA quantities similar to micro-pellets exposed to TGF- $\beta 1$ for 21 days. These results suggested that either BMSCs responded differently to TGF- $\beta 1$ in micro- and macro-pellet models, or that the model significantly influences the perceived kinetics.

Histological matrix characterisation of BMSC micro- or macro-pellets indicated that cells likely responded similarly to TGF- $\beta 1$ exposure, but that the micro- or macro-pellet models significantly influenced perceived kinetics. Radially heterogenous GAG matrix deposition in macropellet histological sections suggested that BMSC differentiation occurred at different rates, depending on the location of the cells within the macro-pellet. Cartilage-like matrix formed first at the outer edge or in small localized regions of macro-pellets, converging incrementally throughout the macro-pellets if TGF- $\beta 1$ exposure was extended. Heterogenous matrix accumulation observed in macro-pellets in our study is similar to previous reports $[4,5,32]$, and perhaps rationalizes the common use of multi-week cultures with continuous TGF- $\beta$ exposure. By contrast, when BMSCs were induced as micro-pellets, their response to TGF- $\beta 1$ appeared more synchronized. A single day of TGF- $\beta 1$ exposure resulted in micro-pellets having relatively uniform cartilage-like matrix distribution that was rich in GAG, and morphologically similar to micro-pellets exposed to TGF- $\beta 1$ for 21 days. Similarly, lacunae structure appeared more mature in micro-pellets, compared with macro-pellets, exposed to a single day of TGF- $\beta 1$. Cumulatively, these data indicate that reduced diffusion gradients in micro-pellets allow synchronized response to TGF- $\beta 1$, revealing that a single day of TGF- $\beta 1$ exposure is sufficient to trigger profound chondrogenic differentiation signaling cascades in BMSCs. By contrast, BMSC macro-pellets were spatially and temporally heterogenous, likely due to steep diffusion gradients. The relative response of ACh to TGF- $\beta 1$ exposure in microvs. macro-pellet culture was not as profound as that of BMSCs. A single day of TGF- $\beta 1$ exposure was insufficient to maximize the cartilage-like matrix output of 21 day ACh cultures. Both ACh micro- and macro-pellets benefited from extended TGF- $\beta 1$ exposure, which increased both DNA and GAG content. Because ACh are a highly committed cell type, unlike multipotent BMSCs, it is possible that TGF- $\beta 1$ serves more to stimulate matrix production in these cells rather than affect the cell phenotype.

We initially used qPCR to compare chondrogenic and hypertrophic gene expression in BMSC and ACh micro- and macro-pellets subjected to different durations of TGF- $\beta 1$ exposure. Brief, 1-3 day exposure of BMSC micro-pellets to TGF- $\beta 1$ was sufficient to upregulate both chondrogenic (SOX9, COL2A1, and ACAN), and hypertrophic (COL1OA1) gene expression to levels seen in cultures exposed to TGF- $\beta 1$ for the full 21 days of induction. By contrast, in ACh micro- and macro-pellets, chondrogenic genes were increased in response to incrementally greater TGF- $\beta 1$ exposure, but this could only be observed with statistical significance for ACAN for one of the two ACh donors analyzed. 
To better understand the transcriptional response to differential TGF- $\beta 1$ exposure, we performed RNA-Seq on BMSCs and ACh micro-pellets. We analyzed data from cultures prior to induction, continuously exposed to TGF- $\beta 1$ and harvested at day $1,3,7$ or 21 , as well as tissues cultured until day 21 after having been exposed to TGF- $\beta 1$ for only 1,3 , or 7 days. This design provided insight into the temporal progression of the differentiation process, as well as opportunity to assess manifestation of programming triggered by different durations of TGF- $\beta 1$ exposure. Each of the three unique BMSC donors generated a similar gene expression signature, progressively upregulating chondrogenic and hypertrophic genes with 1, 3, 7 or 21 days of TGF- $\beta 1$ exposure. We assessed gene expression related to cartilage and bone development that was significantly differentially expressed more than 2 log fold between BMSCs and ACh following TGF- $\beta 1$ exposure and categorized them by their function including those related to transcription factors, soluble signals and receptors, and ECM molecules and ECM biosynthesis.

SP7, or Osterix, is a transcription factor that drives hypertrophy [36] and is required for bone formation [37], and was found to be exclusively upregulated in BMSC in our study, with as little as 1 day of TGF- $\beta 1$ exposure. One-day of TGF- $\beta 1$ exposure resulted in a 9.7 log fold difference in SP7 expression in BMSCs, compared with ACh cultures, and remained highly expressed following TGF$\beta 1$ withdrawal from BMSCs. RUNX2, the master regulator of osteoblast differentiation, was expressed in our BMSC cultures $6.4 \mathrm{log}$ fold more than in ACh cultures prior to chondrogenic induction. This baseline expression of RUNX2 does not increase significantly in BMSC following TGF$\beta 1$ exposure, suggesting that RUNX2 does not induce hypertrophy in BMSCs on its own, but likely requires TGF- $\beta 1$ mediated upregulation of other transcription factors, such as SP7, for hypertrophic conversion. Previous studies have shown that knockdown of $S p 7$ in mice results in diminished hypertrophy in bone progenitor cells in vivo [36]. While molecular inhibitors of SP7 have not been reported, it would be of interest to determine whether regulation of SP7 through knockdown in BMSCs could lead to high-quality, stable hyaline cartilage tissue that does not undergo hypertrophy.

We also identified the expression of soluble signalling factors associated with hypertrophy in BMSC belonging to the WNT and TGF- $\beta 1$ superfamily signalling pathways, including BMP2 and WNT11. Inhibition of these factors in BMSC chondrogenic induction cultures has been previously reported with some success $[32,35]$. Further improvement may be realized using combinations of these inhibitors in micro-pellet cultures as described here, at the time of pellet initiation, as hypertrophic fate commitment occurs with a single day of TGF- $\beta 1$ exposure in BMSCs.

ECM molecules associated with BMSC hypertrophy and mineralization, such as COL1OA1 and IBSP, were not statistically differentially expressed between BMSC and ACh until more than 1-day of TGF- $\beta 1$ exposure. ECM molecules and their biosynthesis are generally downstream products of transcriptional and receptor signalling machinery and, as such, it is not surprising that a relative delay in their gene expression might be observed. Expression of ECM associated genes can serve as good markers for assessing cartilage hypertrophy and tissue quality, but upstream targets are more likely, and feasible, to successfully mitigate hypertrophy.

Comparative analysis of RNA-Seq data from BMSC and ACh micro-pellets provides a number of useful insights into the pathways that differ between these cell populations, identifies potential target pathways to obstruct BMSC hypertrophy, and genes that could be used in reporter assays to facilitate development of chondrogenic media, cell processing, and scaffolding. Our results suggest that BMSC chondrogenic and hypertrophic differentiation is induced following a brief 1-day exposure to TGF- $\beta 1$. Future efforts to generate stable cartilage-like tissue should focus on 


\section{Preprint article - Futrega et al., 25 Nov 2019}

manipulation of the culture conditions over the first few hours of culture induction, including early efforts to obstruct hypertrophy. It is likely unrealistic to expect to identify and characterize these early events using a heterogenous readout, like a macro-pellet or macroscopic tissue model(s). While it may be necessary to develop macroscopic scaffold or gel delivery solutions for cartilage defect repair, addressing basic biological questions will require models not confounded by spatial heterogeneity. More sensitive or responsive models, such as the micro-pellet, will enable bioprocess approaches [38] to be exploited, enabling systematic progression towards optimal culture conditions. Generating high-quality hyaline cartilage is likely to require multiple factors in parallel or in sequence. Previous studies examined the influence of sequential growth factor stimulation at different days in macro-pellet cultures [11,39, 40], likely overshooting the period where BMSCs are most sensitive to instruction. Using a micro-pellet model, or other homogeneous model, focused on guiding cell fate over the first hours or days of culture is more likely to reveal the growth factor combinations required to generate high-quality stable cartilage tissue.

\section{Conclusion}

While BMSCs may have significant unrealized potential in cartilage tissue engineering, current chondrogenic differentiation protocols yield sub-optimal cartilage-like tissue with a hypertrophic propensity [1]. The majority of BMSC chondrogenesis studies characterise the influence of growth factors alone or in combination over multiple days or multiple weeks of culture. Using a micro-pellet model, we discovered that BMSCs respond to a single day of the canonical signalling molecule, TGF- $\beta 1$, engaging both chondrogenic and hypertrophic differentiation pathways. This discovery is significant as it identifies that minimal TGF- $\beta 1$ is required to engage this differentiation process, and that culture optimisation should focus on the first few hours or days of induction. Using more homogeneous small diameter tissue culture models, it may be possible to overcome current limitations in BMSC-mediated cartilage defect repair.

\section{Materials and Methods}

\section{Human BMSC isolation and expansion}

BMSC cultures were established using $20 \mathrm{~mL}$ of heparinized bone marrow aspirate (BMA) collected from the iliac crests of consenting normal adult human donors at the Mater Hospital, Brisbane, Australia. Ethics approval for aspirate collection was granted by the Mater Health Services Human Research Ethics Committee and the Queensland University of Technology Human Ethics Committee (Ethics number: 1000000938). BMSCs were collected as previously described [5] with the exception of donor 3, which was not enriched for mononuclear cells prior to plastic attachment overnight. BMSC donor details were as follows: 24-year-old male (BMSC 1), 44-year-old male (BMSC 2), 21year-old female (BMSC 3), and 43-year-old male (BMSC 4). BMSC expansion medium contained low glucose DMEM with GlutaMAX and pyruvate, $10 \%$ fetal bovine serum (FBS), $100 \mathrm{U} / \mathrm{ml}$ penicillin/streptomycin (PenStrep), all from Thermo Fisher, $10 \mathrm{ng} / \mathrm{mL}$ fibroblast growth factor-1 (FGF-1; Peprotech), and $5 \mu \mathrm{g} / \mathrm{mL}$ porcine heparin sodium salt (Sigma). Cells were distributed into five T175 culture flasks with $35 \mathrm{~mL}$ of expansion medium per flask and were allowed to attach to the plastic surface overnight in a $20 \% \mathrm{O}_{2}, 5 \% \mathrm{CO}_{2}$ and $37{ }^{\circ} \mathrm{C}$ incubator. The medium was replaced after 24 hours to remove loose cells and cell expansion was continued in a reduced oxygen atmosphere, $2 \% \mathrm{O}_{2}, 5 \% \mathrm{CO}_{2}$ and $37{ }^{\circ} \mathrm{C}$ incubator. At $80 \%$ confluence, cells were passaged using $0.25 \%$ trypsin/EDTA (Thermo Fisher) and fresh flasks were re-seeded at $\sim 1,500$ cells per $\mathrm{cm}^{2}$. All BMSC donor cells had undergone cryopreservation in $90 \%$ FBS and $10 \%$ DMSO, thawed, and induced at passage 3 . 
bioRxiv preprint doi: https://doi.org/10.1101/853556; this version posted November 26,2019 . The copyright holder for this preprint (which was not certified by peer review) is the author/funder, who has granted bioRxiv a license to display the preprint in perpetuity. It is made available under aCC-BY-NC-ND 4.0 International license.

Preprint article - Futrega et al., 25 Nov 2019

\section{Human articular chondrocyte expansion}

Normal human articular chondrocytes (ACh) from the knee were purchased from Lonza. Based on the manufacturer's information sheet the cells were cryopreserved at passage 2, and donor information was as follows: 34-year-old male (Lot\#: BF3339; ACh 1 in this study) and 50-year-old male (Lot\#: BF3307; ACh 2). After thawing, these cells were grown as described for BMSCs above, in a $2 \% \mathrm{O}_{2}, 5 \% \mathrm{CO}_{2}$ and $37^{\circ} \mathrm{C}$ incubator and induced at passage 6 .

\section{Chondrogenic-induction cultures}

Chondrogenic induction media consisted of high glucose DMEM supplemented with GlutaMAX and pyruvate, $1 \mathrm{X}$ insulin-transferrin-selenium-ethanolamine (ITS-X), PenStrep, all from Thermo Fisher, $200 \mu \mathrm{M}$ ascorbic acid 2-phosphate (Sigma), $40 \mu \mathrm{g} / \mathrm{mL}$ I-proline (Sigma), and $10 \mathrm{ng} / \mathrm{mL} \mathrm{TGF}-\beta 1$ (Peprotech) where specified. The cells in the "Day 0" TGF-B1 removal condition were never supplemented with TGF- $\beta 1$. The cells were force-aggregated in the well plates by centrifugation at $500 \times g$ for 3 minutes. Full medium exchanges were performed every 2 days or on specified day of TGF- $\beta 1$ removal. For TGF- $\beta 1$ removal, the cell pellets were rinsed once with PBS, then fresh induction medium without TGF- $\beta 1$ was added.

For macro-pellet cultures, cells were seeded in 96-well plates containing deep v-bottom wells (Sigma, Cat\#: 3960), such that each well or aggregate contained $2 \times 10^{5}$ cells per well in $1 \mathrm{~mL}$ of culture medium. The construction of microwell-mesh plates, including necessary materials, plate sterilisation and characterization is described in detail in [5]. These plates contain an array of polydimethylsiloxane (PDMS) pyramidal microwells $(2 \times 2 \times 0.8 \mathrm{~mm})$, covered with a nylon (6/6) mesh (36 $\mu \mathrm{m}$ pore opening). The PDMS microwells enable the formation of many cellular micropellets, simultaneously, while the nylon mesh prevents displacement of the micro-pellets from microwells over long-term culture. An animation demonstrating how the Microwell-mesh platform functions to efficiently manufacture hundreds of micro-pellets is available here [41]. In micro-pellet cultures, cells were seeded at $1.25 \times 10^{6}$ per well of a 6 -well plate. At this seeding density, $\sim 250$ micropellets are formed in each well, with each micro-pellet containing $\sim 5,000$ BMSC. Each well contained $4 \mathrm{~mL}$ of total culture medium.

\section{GAG and DNA quantification}

GAG and DNA was analyzed as previously described [5]. Briefly, tissues were papain (Sigma) digested overnight at $60^{\circ} \mathrm{C}$. GAG was quantified using the 1,9-dimethymethylene blue (Sigma) assay, using chondroitin sulfate from shark cartilage (Sigma) to generate a standard curve. DNA was quantified using the PicoGreen assay kit (Thermo Fisher). Four replicate samples were analysed for each unique cell donor and the means were compared to respective Day $21+$ TGF- $\beta 1$ control cultures.

\section{RNA Isolation}

Samples were crushed in RLT buffer (Qiagen) containing $\beta$-mercaptoethanol (Sigma) and RNA was isolated using the RNeasy Mini Kit (Qiagen) with on-column DNase I (Qiagen) digestion, as per manufacturer's instructions. RNA concentrations were determined using a NanoDrop 1000 (Thermo Fisher).

\section{Quantitative-PCR (qPCR) Analysis}

cDNA was synthesized from total RNA using SuperScript III First-Strand Synthesis System for RT-PCR (Thermo Fisher), as per manufacturer's instructions. qPCR reactions were prepared using SYBR Green PCR Master Mix (Applied Biosystems). Three technical replicates were loaded for each of the 4 biological replicates per donor in 384 well plates and analysed on a Viia7 Real Time PCR System 


\section{Preprint article - Futrega et al., 25 Nov 2019}

(Applied Biosystems). The forward and reverse primer sequence for target genes, as well as the qPCR run parameters have been previously published [5]. Target gene expression was normalized to GAPDH expression and calculated using the $\Delta \mathrm{Ct}$ method. Statistically significant differences in relative gene expression levels for each donor were determined using one-way ANOVA in GraphPad Prism 7.0.

\section{Subcutaneous implantation of cartilage defect model}

NOD/LtSz-scid IL2R gamma null (NSG) mice were purchased from the Jackson Laboratory and bred in the Animal Facility at the Translational Research Institute (TRI) in Brisbane. The University of Queensland (UQ) and the Queensland University of Technology (QUT) Animal Ethics Committees authorized the animal procedures described here. All animal procedures were carried out in accordance with the approved guidelines (Ethics numbers: AEMAR53777 and AEMAR53765). Artificial cartilage defect models were prepared from bovine tissue as previously described [5]. Briefly, plugs containing cartilage and bone were drilled out from bovine knees using a $10 \mathrm{~mm}$ coring bit. Full thickness cartilage defects were drilled out of the plug using a $3.5 \mathrm{~mm}$ drill bit. The defects were washed of debris and sterilized in $70 \%$ ethanol for 24 hours and washed $3 x$ in PBS over another 24 hours. The PBS was discarded, and the defects were kept frozen at $-20^{\circ} \mathrm{C}$ until use. The defects were filled with 21-day cultured micro-pellets that were grown in the presence of TGF- $\beta 1$ for 21 days, or had TGF- $\beta 1$ withdrawn at earlier timepoints, and sealed with fibrin glue (one drop of fibrinogen, followed by one drop of thrombin) (Tisseel, Baxter). Each defect was implanted subcutaneously in a pocket made on the back of an anaesthetized NSG mouse and the skin stapled to close the wound. These tissues were permitted to incubate in NSG mice for 8 weeks, at which point the animals were euthanized and the tissues recovered for analysis.

\section{microCT Analysis}

Tissues excised from mice were fixed in 4\% paraformaldehyde (PFA) for 24 hours and scanned in plastic tubes containing $70 \%$ alcohol and styrofoam to reduce movement. MicroCT analysis was performed to detect hard tissue formation using an Inveon PET-CT Scanner (Siemens; $27.6 \mu \mathrm{m}$ pixel, $60 \mathrm{kV}, 350 \mu \mathrm{A}, 2.5 \mathrm{~s}$ exposure) or the SkyScan 1272 (Bruker; 17-22 $\mathrm{mm}$ pixel, $50 \mathrm{kV}, 200 \mu \mathrm{A}, 0.25 \mathrm{~mm}$ Al filter, $425 \mathrm{~ms}$ exposure). Reconstruction and imaging was performed using Inveon Software (Siemens) or NRecon Software and DataViewer Sofware (Skyscan Bruker) for related machines.

\section{Histology}

Tissues induced for 21 days were fixed in 4\% PFA for 30 minutes, washed and frozen in Tissue-Tek OCT compound (Sakura Finetek). Samples were cryosectioned at $7 \mu \mathrm{m}$ and collected onto polylysine coated slides (Thermo Fisher). After microCT analysis, tissues excised from mice were decalcified in EDTA solution until soft, dehydrated, paraffin embedded and sectioned at $5 \mu \mathrm{m}$. Sections were stained with Toluidine blue (Sigma) for glycosaminoglycan (GAG).

\section{RNA-Seq}

Total RNA was collected from BMSC and ACh cultures prepared in microwell-mesh plates on day 0 , $1,3,7$ and 21 , with or without TGF- $\beta 1$ washout, as indicated. "Day 0" cells represent expanded cells that were not induced. RNA integrity was confirmed using the Agilent 2100 Bioanalyser (Agilent Technologies). Next-generation sequencing and primary bioinformatics was performed by the Australian Genome Research Facility (AGRF, Melbourne) using the Illumina HiSeq 2500 platform (100 bp single end run). AGRF analysis involved demultiplexing, quality control, and then data was processed through RNA-seq expression analysis workflow, which included alignment, transcript assembly, quantification, normalisation, and differential gene expression analysis (Bioconductor $\mathrm{R}$ package edgeR [42]). Significance of differentially expressed genes between ACh and BMSC cultures 
bioRxiv preprint doi: https://doi.org/10.1101/853556; this version posted November 26, 2019. The copyright holder for this preprint (which was not certified by peer review) is the author/funder, who has granted bioRxiv a license to display the preprint in perpetuity. It is made available under aCC-BY-NC-ND 4.0 International license.

\section{Preprint article - Futrega et al., 25 Nov 2019}

was considered at an adjusted $p$-value (FDR) of $<0.05$. Heatmaps were generated using the heatmap. 2 function in the $R$ gplots package [43].

\section{Statistical Analysis}

The quantification of GAG/DNA and qPCR are presented as mean \pm SD ( $n=4$ for each cell donor). Statistical analysis was performed using ANOVA in GraphPad Prism version 7. P-values of 0.05 or less were considered statistically significant.

\section{Data Availability}

Data supporting the conclusions of this paper are available from the corresponding author upon request.

\section{Acknowledgments}

The Translational Research Institute (TRI) is supported by Therapeutic Innovation Australia (TIA). TIA is supported by the Australian Government through the National Collaborative Research Infrastructure Strategy (NCRIS) program. KF and MRD thank the TRI Biological Resource Facility for help with animal studies, the TRI Preclinical Imaging Facility for help with microCT analysis, the TRI Histology Facility for help with tissue processing and sectioning, the Mater Hospital for BMA collection, and the Australian Genome Research Facility (AGRF) for RNA-seq and bioinformatics analysis. KF and MRD gratefully acknowledge project support from the National Health and Medicine Research Council (NHMRC) of Australia (Project Grant APP1083857) and NHMRC Fellowship support of MRD (APP1130013). PGR is supported by the Division of Intramural Research (DIR) of the National Institute of Dental and Craniofacial Research (NIDCR), a part of the Intramural Research Program (IRP) of the National Institutes of Health (NIH), Department of Health and Human Services (DHHS) (1 ZIA DE000380 35). The authors would like to thank Ms Ena Music and abpLearning for generously producing the Microwell-mesh animation.

\section{$\underline{\text { References }}$}

1. Somoza, R.A., J.F. Welter, D. Correa, and A.I. Caplan, Chondrogenic differentiation of mesenchymal stem cells: challenges and unfulfilled expectations. Tissue Eng Part B Rev, 2014. 20(6): p. 596-608.

2. Sacchetti, B., A. Funari, S. Michienzi, S. Di Cesare, S. Piersanti, I. Saggio, E. Tagliafico, S. Ferrari, P.G. Robey, M. Riminucci, and P. Bianco, Self-renewing osteoprogenitors in bone marrow sinusoids can organize a hematopoietic microenvironment. Cell, 2007. 131(2): $p$. 324-36.

3. Hunziker, E.B., T.M. Quinn, and H.J. Hauselmann, Quantitative structural organization of normal adult human articular cartilage. Osteoarthritis Cartilage, 2002. 10(7): p. 564-72.

4. Markway, B.D., G.K. Tan, G. Brooke, J.E. Hudson, J.J. Cooper-White, and M.R. Doran, Enhanced chondrogenic differentiation of human bone marrow-derived mesenchymal stem cells in low oxygen environment micropellet cultures. Cell Transplant, 2010. 19(1): p. 29-42.

5. Futrega, K., J.S. Palmer, M. Kinney, W.B. Lott, M.D. Ungrin, P.W. Zandstra, and M.R. Doran, The microwell-mesh: A novel device and protocol for the high throughput manufacturing of cartilage microtissues. Biomaterials, 2015. 62: p. 1-12.

6. Johnstone, B., T.M. Hering, A.I. Caplan, V.M. Goldberg, and J.U. Yoo, In vitro chondrogenesis of bone marrow-derived mesenchymal progenitor cells. Exp Cell Res, 1998. 238(1): p. 26572. 
bioRxiv preprint doi: https://doi.org/10.1101/853556; this version posted November 26, 2019. The copyright holder for this preprint (which was not certified by peer review) is the author/funder, who has granted bioRxiv a license to display the preprint in perpetuity. It is made available under aCC-BY-NC-ND 4.0 International license.

Preprint article - Futrega et al., 25 Nov 2019

7. Freyria, A.M. and F. Mallein-Gerin, Chondrocytes or adult stem cells for cartilage repair: the indisputable role of growth factors. Injury, 2012. 43(3): p. 259-65.

8. Goldberg, A., K. Mitchell, J. Soans, L. Kim, and R. Zaidi, The use of mesenchymal stem cells for cartilage repair and regeneration: a systematic review. J Orthop Surg Res, 2017. 12(1): p. 39.

9. Jakobsen, R.B., E. Ostrup, X. Zhang, T.S. Mikkelsen, and J.E. Brinchmann, Analysis of the effects of five factors relevant to in vitro chondrogenesis of human mesenchymal stem cells using factorial design and high throughput mRNA-profiling. PLoS One, 2014. 9(5): p. e96615.

10. Puetzer, J.L., J.N. Petitte, and E.G. Loboa, Comparative review of growth factors for induction of three-dimensional in vitro chondrogenesis in human mesenchymal stem cells isolated from bone marrow and adipose tissue. Tissue Eng Part B Rev, 2010. 16(4): p. 435-44.

11. Handorf, A.M. and W.J. Li, Induction of mesenchymal stem cell chondrogenesis through sequential administration of growth factors within specific temporal windows. J Cell Physiol, 2014. 229(2): p. 162-71.

12. Vinatier, C., D. Mrugala, C. Jorgensen, J. Guicheux, and D. Noel, Cartilage engineering: $a$ crucial combination of cells, biomaterials and biofactors. Trends Biotechnol, 2009. 27(5): p. 307-14.

13. McMurtrey, R.J., Analytic Models of Oxygen and Nutrient Diffusion, Metabolism Dynamics, and Architecture Optimization in Three-Dimensional Tissue Constructs with Applications and Insights in Cerebral Organoids. Tissue Eng Part C Methods, 2016. 22(3): p. 221-49.

14. Akkerman, N. and L.H. Defize, Dawn of the organoid era: $3 D$ tissue and organ cultures revolutionize the study of development, disease, and regeneration. Bioessays, 2017. 39(4).

15. Babur, B.K., M. Kabiri, T.J. Klein, W.B. Lott, and M.R. Doran, The rapid manufacture of uniform composite multicellular-biomaterial micropellets, their assembly into macroscopic organized tissues, and potential applications in cartilage tissue engineering. PLoS One, 2015. 10(5): p. e0122250.

16. Jax. Mouse Genome Database (MGD), Gene Ontology (GO). (Accessed on 20 Oct 2019); Available from: http://www.informatics.jax.org/vocab/gene ontology/.

17. Selleri, L., M.J. Depew, Y. Jacobs, S.K. Chanda, K.Y. Tsang, K.S. Cheah, J.L. Rubenstein, S. O'Gorman, and M.L. Cleary, Requirement for Pbx1 in skeletal patterning and programming chondrocyte proliferation and differentiation. Development, 2001. 128(18): p. 3543-57.

18. DeLaurier, A., R. Schweitzer, and M. Logan, Pitx1 determines the morphology of muscle, tendon, and bones of the hindlimb. Dev Biol, 2006. 299(1): p. 22-34.

19. He, G., S. Tavella, K.P. Hanley, M. Self, G. Oliver, R. Grifone, N. Hanley, C. Ward, and N. Bobola, Inactivation of Six2 in mouse identifies a novel genetic mechanism controlling development and growth of the cranial base. Dev Biol, 2010. 344(2): p. 720-30.

20. Harris, L., L.A. Genovesi, R.M. Gronostajski, B.J. Wainwright, and M. Piper, Nuclear factor one transcription factors: Divergent functions in developmental versus adult stem cell populations. Dev Dyn, 2015. 244(3): p. 227-38.

21. Bobick, B.E. and J. Cobb, Shox2 regulates progression through chondrogenesis in the mouse proximal limb. J Cell Sci, 2012. 125(Pt 24): p. 6071-83.

22. Hartmann, C. and C.J. Tabin, Dual roles of Wnt signaling during chondrogenesis in the chicken limb. Development, 2000. 127(14): p. 3141-59. 
bioRxiv preprint doi: https://doi.org/10.1101/853556; this version posted November 26, 2019. The copyright holder for this preprint (which was not certified by peer review) is the author/funder, who has granted bioRxiv a license to display the preprint in perpetuity. It is made available under aCC-BY-NC-ND 4.0 International license.

Preprint article - Futrega et al., 25 Nov 2019

23. Church, V., T. Nohno, C. Linker, C. Marcelle, and P. Francis-West, Wht regulation of chondrocyte differentiation. J Cell Sci, 2002. 115(Pt 24): p. 4809-18.

24. Datta, N.S. and A.B. Abou-Samra, PTH and PTHrP signaling in osteoblasts. Cell Signal, 2009. 21(8): p. 1245-54.

25. Minina, E., C. Kreschel, M.C. Naski, D.M. Ornitz, and A. Vortkamp, Interaction of FGF, Ihh/Pthlh, and BMP signaling integrates chondrocyte proliferation and hypertrophic differentiation. Dev Cell, 2002. 3(3): p. 439-49.

26. Chen, H., T.D. Capellini, M. Schoor, D.P. Mortlock, A.H. Reddi, and D.M. Kingsley, Heads, Shoulders, Elbows, Knees, and Toes: Modular Gdf5 Enhancers Control Different Joints in the Vertebrate Skeleton. PLoS Genet, 2016. 12(11): p. e1006454.

27. Wang, W., D. Rigueur, and K.M. Lyons, TGFbeta signaling in cartilage development and maintenance. Birth Defects Res C Embryo Today, 2014. 102(1): p. 37-51.

28. Liu, Z., J. Xu, J.S. Colvin, and D.M. Ornitz, Coordination of chondrogenesis and osteogenesis by fibroblast growth factor 18. Genes Dev, 2002. 16(7): p. 859-69.

29. Negoro, T., Y. Takagaki, H. Okura, and A. Matsuyama, Trends in clinical trials for articular cartilage repair by cell therapy. NPJ Regen Med, 2018. 3: p. 17.

30. Narcisi, R., M.A. Cleary, P.A. Brama, M.J. Hoogduijn, N. Tuysuz, D. ten Berge, and G.J. van Osch, Long-term expansion, enhanced chondrogenic potential, and suppression of endochondral ossification of adult human MSCs via WNT signaling modulation. Stem Cell Reports, 2015. 4(3): p. 459-72.

31. Yang, Z., Y. Zou, X.M. Guo, H.S. Tan, V. Denslin, C.H. Yeow, X.F. Ren, T.M. Liu, J.H. Hui, and E.H. Lee, Temporal activation of beta-catenin signaling in the chondrogenic process of mesenchymal stem cells affects the phenotype of the cartilage generated. Stem Cells Dev, 2012. 21(11): p. 1966-76.

32. Occhetta, P., S. Pigeot, M. Rasponi, B. Dasen, A. Mehrkens, T. Ullrich, I. Kramer, S. GuthGundel, A. Barbero, and I. Martin, Developmentally inspired programming of adult human mesenchymal stromal cells toward stable chondrogenesis. Proc Natl Acad Sci U S A, 2018. 115(18): p. 4625-4630.

33. Ng, J.J., Y. Wei, B. Zhou, J. Bernhard, S. Robinson, A. Burapachaisri, X.E. Guo, and G. VunjakNovakovic, Recapitulation of physiological spatiotemporal signals promotes in vitro formation of phenotypically stable human articular cartilage. Proc Natl Acad Sci U S A, 2017. 114(10): p. 2556-2561.

34. Kuznetsov, S.A., A. Hailu-Lazmi, N. Cherman, L.F. de Castro, P.G. Robey, and R. Gorodetsky, In Vivo Formation of Stable Hyaline Cartilage by Naive Human Bone Marrow Stromal Cells with Modified Fibrin Microbeads. Stem Cells Transl Med, 2019. 8(6): p. 586-592.

35. Diederichs, S., V. Tonnier, M. Marz, S.I. Dreher, A. Geisbusch, and W. Richter, Regulation of WNT5A and WNT11 during MSC in vitro chondrogenesis: WNT inhibition lowers BMP and hedgehog activity, and reduces hypertrophy. Cell Mol Life Sci, 2019. 76(19): p. 3875-3889.

36. Kaback, L.A., Y. Soung do, A. Naik, N. Smith, E.M. Schwarz, R.J. O'Keefe, and H. Drissi, Osterix/Sp7 regulates mesenchymal stem cell mediated endochondral ossification. J Cell Physiol, 2008. 214(1): p. 173-82.

37. Rashid, H., C. Ma, H. Chen, H. Wang, M.Q. Hassan, K. Sinha, B. de Crombrugghe, and A. Javed, Sp7 and Runx2 molecular complex synergistically regulate expression of target genes. Connect Tissue Res, 2014. 55 Suppl 1: p. 83-7. 
bioRxiv preprint doi: https://doi.org/10.1101/853556; this version posted November 26, 2019. The copyright holder for this preprint (which was not certified by peer review) is the author/funder, who has granted bioRxiv a license to display the preprint in perpetuity. It is made available under aCC-BY-NC-ND 4.0 International license.

\section{Preprint article - Futrega et al., 25 Nov 2019}

38. Lipsitz, Y.Y., P. Bedford, A.H. Davies, N.E. Timmins, and P.W. Zandstra, Achieving Efficient Manufacturing and Quality Assurance through Synthetic Cell Therapy Design. Cell Stem Cell, 2017. 20(1): p. 13-17.

39. Indrawattana, N., G. Chen, M. Tadokoro, L.H. Shann, H. Ohgushi, T. Tateishi, J. Tanaka, and A. Bunyaratvej, Growth factor combination for chondrogenic induction from human mesenchymal stem cell. Biochem Biophys Res Commun, 2004. 320(3): p. 914-9.

40. Correa, D., R.A. Somoza, P. Lin, S. Greenberg, E. Rom, L. Duesler, J.F. Welter, A. Yayon, and A.I. Caplan, Sequential exposure to fibroblast growth factors (FGF) 2, 9 and 18 enhances hMSC chondrogenic differentiation. Osteoarthritis Cartilage, 2015. 23(3): p. 443-53.

41. Futrega, K. Microwell-mesh animation. 2019 [cited 2019 November 29]; Available from: https://youtu.be/mhp8k bGtCw

42. Robinson, M.D., D.J. McCarthy, and G.K. Smyth, edgeR: a Bioconductor package for differential expression analysis of digital gene expression data. Bioinformatics, 2010. 26(1): p. 139-40.

43. Warnes, G.R.B., B.; Bonebakker, L.; Gentleman, R.; Huber, W.; Liaw, A.; Lumley, T.; Maechler, M.; Magnusson, A.; Moeller, S.; Schwartz, M.; Venables, B. gplots: Various R Programming Tools for Plotting Data. Version 3.0.1.1. 2015 (Accessed on 20 Oct 2019); Available from: https://cran.r-project.org/package=gplots. 